\title{
Trayectorias hacia la libertad individual: el uso de la ironía en la novela $E l$ héroe discreto de Mario Vargas Llosa.
}

\author{
Vigdis Ahnfelt (Dep. Lengua, Literatura y Estudios Interculturales - \\ Karlstad University, Suecia)
}

\begin{abstract}
The present study examines the spiritual development of the main characters in the novel The Discreet Hero (2013) by Mario Vargas Llosa, and the aim is to show how irony provides the reader with reflections upon the meaning of individual freedom. The hypothesis suggests that the characters, representing different social and cultural groups of today's Peruvian society, try to free themselves from surrounding threats and thereby obtain what Isaiah Berlin (1971) terms negative or positive freedom.

The analysis focuses on narrative irony, which operates on three levels of the text: firstly, what it linguistically hides by telling something different, secondly, the discrepancy that emerges between narration and what lies underneath and thirdly, the dialectic ideas that impregnate the text and transmit the ambiguity of the work (Tittler 1984). Ethical irony, according to which the characters of narrative are incoherent figures that pursue coherence (Handwerk 1985), is also included. The study shows that irony problematizes in what ways the characters perceive individual freedom. All of them experience negative freedom, which emerges when authorities fail in their support and protection of the citizens despite political and economic freedom. In order to obtain positive freedom, individual ethical and social responsibility, knowledge of self and cultural refinement are essential. Through irony, it becomes clear that positive freedom depends on a democratic society and individual values.
\end{abstract}

Keywords: narrative irony, ethical irony, negative freedom, positive freedom, Mario Vargas Llosa

El escritor Mario Vargas Llosa es famoso por un gran universo narrativo y numerosos ensayos en los que presenta sus ideas sobre política, cultura y literatura (Angvik 1987; Enkvist 2006; Köllmann 2014). En 2010 recibió el Premio Nobel, y la primera obra a publicarse después de aquel evento fue El héroe discreto (2013), ${ }^{1}$ una novela que, parecido a relatos anteriores, se caracteriza por riqueza narrativa, humor e ironía ${ }^{2}$ (Fernández-Lamarque 2013, Ramírez 2013). Además, destaca valores como el coraje y el honor del individuo en

\footnotetext{
${ }^{1}$ El título de esta novela se abreviará $E H D$. Las citas se indicarán mediante el número de página entre paréntesis.

${ }^{2}$ La ironía predomina en la novela La tía Julia y el escribidor (Tittler 1984,28), también en La ciudad y los perros y en Pantaleón y las visitadoras (Köllmann 2014, 89, 139).
} 
relación con un mundo que lo ignora u oprime (Goldman March 2015). Las tramas de EHD se vinculan a obras anteriores mediante referencias a lugares y personajes ${ }^{3}$. La crítica negativa apunta que no es la novela más destacada del autor (Marco 2013) y que se reduce a una historia de conflictos de familia (Mendoza 2017).

Según Vargas Llosa, EHD es su novela más optimista cuyo trasfondo es la democracia del Perú actual, una sociedad que ofrece plena libertad a los ciudadanos. El autor explica que se tematiza cómo los personajes enfrentan la corrupción surgida a causa del desarrollo económico, si aceptan someterse a los problemas o conservar la decencia. ${ }^{4}$ A partir de esto pensamos que EHD también ofrece reflexiones acerca del tema de la libertad, un asunto que el escritor según Köllmann (2014, 65 - 66) problematiza en la colección de ensayos Desafíos a la libertad (1990 - 1994), inspirado por las ideas de Isaiah Berlin y Karl Popper. Conforme a la misma estudiosa (Köllmann 2014, 21), en el discurso del Premio Nobel, Vargas Llosa resalta "the coexistence of differing ideas; understanding and tolerance of 'the other'; and, above all, freedom" como temas importantes de su narrativa.

A nuestro juicio, en $E H D$ la corrupción y el machismo representan formas de opresión que los personajes tienen que enfrentar. Les toca someterse o liberarse de ellas, y nos interesa por tanto averiguar cómo se configuran estas luchas, en qué medida y de qué manera los personajes se pueden considerar libres. Los personajes representan varios grupos sociales y viven situaciones en las que emerge la ironía que a su vez genera la ambigüedad del texto. Así se puede interpretar una crítica social hacia el Perú democrático de hoy, la cual implica que la libertad del individuo no solo significa libertad económica y política sino también se requiere el autoconocimiento y la responsabilidad ética por parte de los ciudadanos.

Para indicar cómo surge la ironía en el texto nos basaremos en las teorías de Tittler (1984) y Handwerk (1985), cuyos postulados coinciden y difieren. Ambos problematizan las teorías de estudiosos anteriores y apuntan que la ironía expresa una cosa criticando otra, ${ }^{5}$ pero mientras Tittler se ocupa de tres dimensiones del texto - la verbal, las acciones y situaciones narradas más la ambigüedad que emerge de ellas - Handwerk se centra en los personajes, explicando que equivalen a sujetos incoherentes que persiguen obtener coherencia. En este proceso, que se dirige hacia el futuro y cuya meta es el consenso, la ironía es esencial. En nuestro estudio, después de presentar aspectos importantes sobre el contenido de $E H D$, proporcionaremos ejemplos de situaciones y reflexiones en las que emerge la ironía. Problematizaremos la ambiguiedad surgida para relatarla a ideas sobre la libertad de Berlin (1971), Popper (1997) y Fromm (2016). A los primeros se incluye porque se ocupan de la libertad del individuo desde las perspectivas sociológica y filosófica, y porque al autor mismo le interesan. Remitiremos al tercero por tratar estados psíquicos en relación con el asunto. De esta manera nos propondremos indicar qué se entiende por libertad individual según este texto de Vargas Llosa.

\footnotetext{
${ }^{3}$ La historia transcurre en Piura y Lima, y se refiere a "Los inconquistables", que frecuentaban La Casa Verde, un prostíbulo que constituye el espacio de la novela que lleva el mismo título (Estruch 2013). Según FernándezLamarque $(2013,364)$ se incluyen el sargento Lituma y el capitán Silva de Historia de Mayta (1984) y ¿Quién mató a Palomino Molero? (1986), también Rigoberto, Lucrecia y Fonchito de Elogio a la madrastra (1988) y Los cuadernos de don Rigoberto (1997).

${ }^{4}$ Véase p.ej. la entrevista a Vargas Llosa efectuada por la Rtv española, Página 2, el día 22 septiembre de 2013 : http://www.rtve.es/alacarta/videos/pagina-dos/pagina-2-entrevista-mario-vargas-llosa-sobre-su-libro-heroediscreto/2027629/ y también la que se ha organizado por la editorial Alfaguara: https://publimetro.pe/actualidad/noticia-video-vargas-llosa-presenta-su-novela-heroe-discreto-16577

${ }^{5}$ P. ej. Wayne C. Booth (1971), Georg Lukács (1971) y de Stanley Fish (1980).
} 
Las dos tramas principales de la novela son paralelas que se cuentan por un narrador omnisciente que a veces cede la palabra a los personajes, cambiando el foco y desplazando al lector en el tiempo y el espacio. ${ }^{6}$ Los capítulos impares versan sobre Felícito Yanaqué, dueño de una empresa de transportes ubicada en Puira. En los demás aparecen don Rigoberto, el abogado de Ismael Carrera, propietario de una aseguradora de Lima. Felícito vive con su esposa Gertrudis con la que tiene los hijos adultos Miguel y Tiburcio. Don Rigoberto está con su mujer Lucrecia, la madrastra de su hijo Fonchito. Aunque Felícito viva en una ciudad provincial y el otro en la gran urbe, ambos tienen que enfrentar dificultades vinculadas a la corrupción y la delincuencia. En los dos relatos aparecen actores que funcionan como entidades de reflexión; la santera Adelaida que vive en Piura, y el presunto amigo de Fonchito, Edilberto Torres, que aparece en Lima. El problema de Felícito es que alguien lo extorsiona, enviándole cartas anónimas firmadas por un "tosco dibujo de lo que parecía una arañita" (12), y así empieza la lucha por liberarse de esta situación. La intriga del otro es que los hijos de don Ismael - viudo desde hace años - desean la muerte del padre para poder heredar su fortuna. Ismael se da cuenta de esta crueldad, decide desheredar a los hijos casándose con su sirvienta Armida. Al cabo de unos meses de felicidad Ismael fallece, y a Rigoberto le toca cumplir con la venganza armada por su jefe y lidiar "las hienas" (36). Hacia el final de la novela los relatos se enlazan de manera azarosa.

Felícito parece estar contento con la vida y cree que todo se debe a la santera Adelaida y al "pulpero Lau" (14), un chino ya fallecido de quien el transportista ha aprendido los ejercicios de Qi Gong que practica diariamente. Al respecto el narrador resume: "Sin ellos nunca le habría ido bien en los negocios, ni hubiera sacado adelante su empresa de transportes, ni constituido una familia honorable, ni tendría esa salud de hierro" (18). O sea, según el protagonista, tanto el equilibrio físico y mental como los éxitos en la vida privada y laboral dependen de la habilidad de otros, no de las cualidades propias. Estas reflexiones revelan que le falta el auto-conocimiento, porque conforme a Tittler $(1984,17)$, emerge la ironía por la discrepancia entre las ideas del personaje y lo que representa el entorno.

Para Felícito las cartas de extorsión representan una ruptura con su vida tranquila. Alguien intenta aprovechar de él, pero como sigue el consejo de su padre de no dejarse nunca "pisotear" (13), decide denunciar el delito. Le sorprende entonces la indiferencia del sargento Lituma que al ver la carta comenta que es "una consecuencia del progreso" (15), le extraña que tanto Adelaida como Mabel le aconsejen ceder a las exigencias de los delincuentes, que su secretaria Josefita le comente que esto sucede "todos los días, ahora en Piura" (14) y que el amigo Colorado Vignolo admita que le pague a la mafia "un pequeño cupo cada mes", asegurando que muchas "compañías de transportes de Piura también pagan esos cupos" (77). De nuevo se nota la discrepancia entre Felícito y su entorno: en una sociedad democrática y próspera impera la corrupción, aceptada por todos, desde las instancias oficiales representadas por el policía Lituma hasta las clases más bajas, representadas por Mabel y Adelaida. En cambio, Felícito lleva mucho tiempo desconociendo esta situación, pero al enterarse del problema resulta ser uno de los pocos que niega a someterse.

Al denunciar el delito el transportista vive una especie de sumisión, lo cual se manifiesta de esta manera: "El interior de la comisaría era un horno y, como todas las ventanas estaban cerradas, se hallaba medio a oscuras" (14-15). El espacio representa un factor opresivo y, como huele "a sudor y vejez" (16), se nota la decadencia. El calor, la

\footnotetext{
${ }^{6}$ Como explica Inger Enkvist $(1987,52)$, a veces la técnica narrativa de Vargas Llosa implica "cambiar de enfoque sin que esto se note como una ruptura".
} 
oscuridad y el hedor crean un ambiente insoportable en el que Felícito se ve obligado a esperar hasta que Lituma "se dignara recibirlo" (15). Mediante el verbo "dignarse" el narrador ironiza la actitud del policía, criticando una instancia oficial democrática que parece ignorar el bien de los ciudadanos. Como las gafas le dan "un aire leguleyo" (15) al policía, que comenta la "buena ortografía" (16) de la carta anónima, se manifiesta una burla hacia el personaje que parece tener una calidad de la que carece y porque habla de cosas que no pertenecen al caso. Esta actitud de Lituma le provoca malestar en el transportista y una sensación de ser ignorado. Siguiendo a Tittler $(1984,17)$, podemos decir que se ironizan la mediocridad, la ignorancia y la indiferencia hacia los ciudadanos por parte de las instancias oficiales.

Como Felícito fracasa en denunciar el delito se dirige a la prensa advirtiéndoles a los chantajistas que no acepta sus exigencias. Así, se convierte en un "héroe" y hombre de fama, elogiado por su valentía y honestidad. No obstante, al revelarse quiénes son los chantajistas, detalles delicados de la vida privada del transportista se exponen en la prensa, de modo que se siente ridiculizado, inhibido y sin protección social. Se nota por tanto la influencia que puede tener la prensa en los ciudadanos, un problema que Felícito le comenta a don Rigoberto: "No sabe usted lo horrible que es volverse conocido, salir en los periódicos y en la televisión, que a uno lo señale la gente en la calle" (379 - 80). El héroe de antes se convierte en una víctima y surge así la crítica hacia la prensa por exponer los hechos de manera torcida, superficial y a coste del individuo. Al mismo tiempo se da un guiño a los que necesitan la prensa y dicen detestarla. De acuerdo a Enkvist $(2006,46)$ y Köllmann $(2014,139)$, esto sería un ejemplo de la auto-ironía de Vargas Llosa.

El caso de Felícito se difunde hasta la capital y tanto el gobierno como la policía son ridiculizados por su negligencia e hipocresía. Al respecto el narrador recapitula la situación en la comisaría donde trabajan el sargento Lituma y el capitán Silva:

El coronel Ríos Pardo, alias Rascachucha, jefe policial de la región, había vuelto a reñirlos la víspera, [...], porque el desafío de Felícito Yanaqué contra los mafiosos en El Tiempo había llegado a Lima. El propio ministro del Interior llamó en persona para exigirle que aquello se resolviera de inmediato. La prensa se había hecho eco del asunto y no sólo la policía, el mismo Gobierno estaba quedando en ridículo [...]. - Tenemos que reivindicar a la policía, carajo- bramó, [...]. Unos cuantos zamarros no pueden reírse de nosotros de esta manera (113).

Se inserta el apodo grosero para indicar complicidad laboral de los subordinados y una manera torpe de humillar al jefe en su afán de complacer a los superiores, un comportamiento hipócrita que impregna el ámbito laboral como sistema jerárquico. Con Tittler (1984, 3) podemos agregar que la ironía emerge en cuanto el superior se enfada porque las deficiencias de la policía se exponen a todo el país, no por los individuos que padecen la delincuencia. A su vez, los inferiores son obligados a comprometerse con el fin de evitar más escándalos, no para proteger a la víctima en su lucha contra el miedo, la delincuencia y la sumisión.

Después de revelarse la identidad de los chantajistas, Felícito decide vengarse. Se comunica con su abogado que, al escuchar sus planes lo describe como "un hombre ético" (310), lo cual hace que el transportista reflexione: "Todo el tiempo estaba escuchando palabras cuyo significado ignoraba. Y le daba vergüenza ir preguntando a la gente lo que querían decir" (310). Como el protagonista desconoce el significado de las palabras no es capaz de entender el elogio de su interlocutor, algo que le hace sentirse inferior. Al respecto 
diría Handwerk (1985, 3 - 4) que la falta de conocimiento le impide al transportista conocerse a sí mismo y así crear coherencia y que, irónicamente, no es consciente de este problema.

En las relaciones con Gertrudis y Mabel se ve que Felícito no siempre es tan ético como dice el abogado. Así reflexiona: "A Gertrudis nunca la quiso, se casó con ella por obligación, debido a aquel mal paso de su juventud y, tal vez, tal vez, porque ella y la Mandona ${ }^{7}$ le tendieron una buena trampa." (44). Al transportista el presunto engaño le provoca malestar, pero no parece reflexionar acerca del estado de su mujer hasta escucharle describir el mismo acontecimiento: "Yo quería abortar donde una comadrona medio bruja que había en el barrio [...]. Pero la Mandona no me lo permitió. [...] Yo tampoco quería casarme contigo, Felícito." (302). Se revela así que Gertrudis es víctima de la explotación sexual. El matrimonio le impide educarse y el remordimiento por el engaño hace que dedique la vida a pagar sus "culpas" (302) yendo a la misa todos los días. Al escuchar esto Felícito piensa que va "a tener otro desmayo y vomitar" (302). O sea, se da cuenta de que lleva muchos años sin conocer la vida de su mujer y al enterarse de su pasado siente malestar porque comprende que involuntariamente contribuye a causar la falta de libertad de su mujer. En línea con Tittler $(1984,18)$ resulta irónico que tanto Gertrudis como Felícito se hayan sometido a las exigencias del entorno, que sean víctimas del machismo y de los prejuicios de la sociedad que los rodea.

La ironía se nota también en la relación con Mabel, a quien el protagonista se cree amar, mientras que para ella él es un cliente importante que le ofrece libertad económica. No obstante, como el amigo Vignolo le aclara que es una "cortesana" que "tira, no que putee" (42), a Felícito la relación le parece legítima. Aquí cabe recordar que según comenta Lituma a su jefe, Mabel vive en el barrio Castilla de Piura, donde antes había un prostíbulo "nefasto" del nombre "la Casa Verde" $(117)^{8}$. Irónicamente, pese al desarrollo económico y el cambio político, la explotación de la mujer y las tristes condiciones sociales del pasado siguen intactas. Además, cuando a Mabel se le ofrece otra forma de vivir, le toca reconsiderar su vida: "Tendría que irse de Piura, tal vez. Pero la idea de vivir sola, en una ciudad desconocida [...], la desmoralizaba. ¿Qué iba a hacer sola su alma en un lugar sin parientes ni amigas?" (215). Por un lado, Mabel es víctima del machismo y de la explotación sexual, un negocio que al mismo tiempo le da libertad económica. Por otro lado, no ve la posibilidad de liberarse de la sumisión, sino la ruptura le equivale un obstáculo.

Al darse cuenta de que Miguel no es su hijo y además un delincuente, Felícito le insulta por ser ilegítimo llamándole "uno de esos siete leches que hay en Piura" (351) y parece ignorar que él mismo ha sido cliente de la madre. Se revela así una situación ambigua: El transportista se enfada con Miguel por ser el producto de acciones causadas por otros, incluso por él mismo. Asimismo, al obligar al joven desaparecerse de Piura, tomar otro apellido y nunca regresar, pretende castigarlo por el dilema moral del padre y no por el chantaje. El otro, a su vez, reacciona con rabia porque tiene que enfrentar la exclusión social.

Según Mendoza (2017), Adelaida no tiene que ver con la trama de la novela, pero a nuestro juicio resulta importante por ser ambigua y a la vez antitética a Gertrudis y Mabel. Es de origen humilde, vive sola fuera del centro de Piura, junto a su tienda donde vende varias cosas y recibe a clientes con problemas personales. Para Felícito es una gran amiga que le

\footnotetext{
${ }^{7}$ La Mandona es el apodo de la madre de Gertrudis, propietaria de El Algarrobo, una pensión que en la juventud de Gertrudis y Felicito funcionaba como prostíbulo frecuentado por Felícito y otros camioneros.

${ }^{8}$ Este burdel es un espacio central en la novela El paraíso en la otra esquina en la que se configura una crítica amarga hacia la explotación sexual de la mujer y el machismo (Köllmann 2014, 106).
} 
ayuda mediante sus momentos de "inspiración" (23). Por ejemplo, al exponerse el escándalo, Adelaida lo escucha, mostrándole compasión y empatía, ofreciendo alivio y protección. Se configura así una relación interpersonal que a Felícito le posibilitaría la auto-realización. Sin embargo, como el narrador en otro momento resume que "a pesar de conocer a Adelaida ya tantos años, la adivinadora seguía siendo para él un gran misterio" (361), se entiende que Felícito carece de conocimiento acerca de ella. Desde el punto de vista irónico, esta amistad resulta engañosa y una ilusión.

Parecido a Felícito, don Rigoberto enfrenta la delincuencia, pero no por chantajistas anónimos sino a causa de los problemas de su jefe. Cuando este le pide que sea testimonio de su boda, Rigoberto piensa que le va a obligar a dar "marcha atrás" (26), lo cual implica postergar la jubilación y el viaje a Europa que lleva preparando desde hace años. Por ello se defiende de manera desesperada: "Me jubilo de todas maneras, aunque me pongas una pistola en el pecho." (27) Rigoberto exagera las consecuencias para mostrar en qué medida pretende estar dispuesto a liberarse de sus obligaciones laborales. Como Ismael se ríe de la respuesta, podemos con Tittler $(1984,17)$, agregar que se configura la ironía intencional, es decir, el personaje expresa reproche hacia el otro sabiendo que este comprende que en el fondo la crítica no es grave.

Los mellizos Miki y Escobita intentan amargarle la vida a Rigoberto parándole los trámites de la jubilación y utilizando la prensa para acusarle de estar involucrado en los presuntos negocios sucios de Ismael. A causa de estas mentiras le toca comunicarse con el "juez instructor" (132) de Ismael, una visita que se describe así: "La oficinita estrecha y asfixiante hervía de calor y de moscas [...]. Sentado en una silla pequeña y raquítica, en la que apenas le cabían la mitad de las nalgas [...], Rigoberto estuvo todo el tiempo haciendo equilibrio para evitar caerse al suelo [...]" (233). Parecido al lugar donde Felícito denuncia el delito, este espacio representa un entorno opresivo. De acuerdo a Tittler $(1984,18)$ podemos agregar que en esta situación cómica subyace lo absurdo respecto a las instancias democráticas: pese al desarrollo económico y la prosperidad, se obliga a los ciudadanos defender la decencia frente a los delincuentes bajo circunstancias incómodas, precarias y sucias.

Las conversaciones mantenidas por Rigoberto y Fonchito versan sobre cuestiones existenciales y la cultura. El adolescente remite a su presunto amigo Edilberto Torres, un personaje que según Mendoza (2017) solo constituye una digresión de la trama. Pero a nuestro juicio, cumple una función importante en la relación entre padre e hijo: contribuye a crear la ironía que a su vez produce la ambigüedad. Como Rigoberto se siente molesto y duda la existencia de Torres, preguntándose si es un pederasta o el diablo, el hijo reproduce la respuesta del amigo: "No soy el diablo ni nada que se le parezca, sino una persona normal y corriente, $[\ldots]$. Además, te equivocas, no me aparezco y desaparezco de manera milagrosa. Nuestros encuentros son obra del azar" (247). A pesar de considerarse un hombre culto, educado y sensato, Rigoberto revela en este caso prejuicios que derivan de las creencias religiosas. Además, si bien Rigoberto representa a la generación mayor - con la que se identifica el autor mismo (Estruch 2013) - y Fonchito equivale a los jóvenes, podemos inferir que en esta relación el adolescente parece saber más que su padre. Así, de acuerdo a Tittler (1984, 26 - 27), la ambigüedad se configura en cuanto Fonchito presenta los comentarios de Torres para que el padre reflexione acerca del azar, de la vida y la cultura.

Si la corrupción y el machismo representan la opresión en $E H D$, el viaje se puede ver como un proyecto de consenso dirigido hacia el futuro (Handwerk 1985, 15 - 17) y frente a 
este proyecto las actitudes de los personajes divergen. Rigoberto le declara con emoción a su hijo que "este viaje será mi obra maestra. La que no pinté, ni compuse, ni escribí, Fonchito. Pero tú la vivirás." (372). A Rigoberto, el viaje constituye una fase importante en su trayectoria hacia una personalidad coherente y cumplida. Al mismo tiempo, sin explicar por qué, el protagonista reconoce su falta de compromiso en los ámbitos culturales. La repuesta del joven es irónica: "Nunca es tarde para eso, papá [...]. Ahora eres jubilado y tienes toda la libertad del mundo para hacer lo que quieras." $(372-73)$. No solo se deduce la auto-ironía de Vargas Llosa en relación con la escritura como actividad profesional (Tittler 1984, 144), sino también que la vida como escritor implica nunca jubilarse (Köllmann 2014, 69).

Mientras Rigoberto se alegra por el viaje, Felícito comenta que "no estaba nada convencido, que el viaje no le hacía la menor ilusión y que, en efecto, se sacrificaba por su mujer" (379). O sea, el transportista pretende realizar el viaje por Gertrudis, pero su excusa resulta ambigua porque ya conoce el triste pasado de su mujer y sabe que el viaje puede ser una manera para ella de recuperarse. Cabe agregar que Felícito supone que Rigoberto no sabe nada de la vida de Gertrudis. En efecto, Rigoberto solo recuerda que durante la visita a Piura unos meses atrás Gertrudis parece traumatizada. Al conversar con Felícito le extraña los cambios de esta mujer que "se había vuelto más comunicativa y simpática, [...] sonreía [...], hablaba ahora sin parar" (377). Al respecto, Felícito evita decir que Gertrudis por primera vez en su vida tiene la oportunidad de romper con la monotonía y el aislamiento en Piura. O bien, si seguimos a Handwerk $(1985,16)$, para Gertrudis el viaje sería un proyecto futuro que le da la posibilidad de obtener coherencia y llegar al consenso. A su vez, Felícito no comprende estas posibilidades de conocer el mundo y a sí mismo, en cambio, el viaje le parece una obligación.

Si bien se ha comentado que Armida parece corresponder a la Cenicienta (Estruch 2013), es preciso subrayar que, como elemento narrativo cumple la función de enlazar los relatos siendo ella la que se refugia a la casa de Gertrudis, su hermana, para evitar las atrocidades de los mellizos. Después de resolverse los problemas, Armida invita a todos a visitarla a Roma. Los rasgos de este personaje se revelan paulatinamente a lo largo de la narración. Al principio, Rigoberto no entiende por qué su jefe decide casarse con ella, una sirvienta ingenua, pero después de la luna de miel observa que se comporta de manera educada. Cuando se terminan los asuntos jurídicos de Ismael, el abogado le comenta a Lucrecia el destino de la viuda: "Ha demostrado ser más viva que todos nosotros juntos. Se ha salido con la suya y allí la tienes ahora, viviendo en Italia, con toda la herencia de Ismael en sus bolsillos." (369). Sin embargo, Lucrecia le contradice: "No hables mal de Armida, no te burles [...]. No es ni fue nunca lo que la gente cree" (369). O sea, Armida no es lo que parece ser al principio, sino el azar, la capacidad de educarse y la responsabilidad ética le han llevado a obtener la libertad económica y el auto-conocimiento. Conforme a Handwerk (1985, 15 17) es incoherente al principio, pero resulta coherente al final de la trama y ofrece así la oportunidad a otros a obtener consenso.

De la ironía se deduce que pese a tener libertad económica y política, los personajes se ven obligados a someterse a problemas que surgen en el entorno. Conforme a Berlin (1971, 122 - 24), todos viven bajo las condiciones de la denominada libertad negativa, la cual implica cierta libertad a tomar decisiones en el ámbito privado y que puede existir tanto en una dictadura como en una democracia. En EHD la corrupción representa una especie de opresión y es aceptada tanto por las instancias oficiales como los ciudadanos en general. Al respecto remitimos a Berlin $(1971,130)$, quien apunta que "there is no necessary connexion 
between individual liberty and democratic rule." Sin embargo, los protagonistas, Felícito, Ismael y Rigoberto, niegan a someterse a las exigencias de los chantajistas. Emprenden por tanto la lucha por la dignidad, la decencia y la libertad individual. Después arman venganzas que a los agresores implica pérdida de libertad. Los mellizos Miki y Escobita pierden la libertad económica, Miguel y Mabel deberían pasar años en la cárcel, pero a causa de la decisión de Felícito, les toca la exclusión social. Frente a esta situación Miguel reacciona con rabia y Mabel con desasosiego y dudas. En relación con esto señalaría Fromm (2016) que, si el precio de la libertad es la exclusión social, se genera el miedo a la libertad, y el hombre preferirá la opresión.

Otra instancia que influye en la vida de los personajes es la prensa. Por un lado, los protagonistas aprovechan de ella al enfrentar los delincuentes, pero Felícito ve una fuerte pérdida de dignidad cuando la prensa expone su vida privada al público. Se siente ridiculizado e inhibido frente al entorno e irónicamente, mediante la prensa pierde lo que intenta conservar. Por lo tanto, en $E H D$ la prensa representa, de acuerdo a Berlin $(1971,130)$ una instancia de la sociedad democrática que puede afectar a los ciudadanos de modo que la libertad individual no es garantizada sino frágil y dependiente del colectivo.

Conforme a Berlin $(1971,131$ - 32) el conocimiento acerca de otros se necesita para conocerse a sí mismo, lo cual es fundamental para obtener la denominada libertad positiva, un concepto que según el pensador (Berlin 1971, 141 - 44) significa el deseo del individuo de ser "his own master". Siguiendo esta línea, Popper (1996, 131 - 32) subraya que el conocimiento del lenguaje forma parte de la conciencia que está ligada a la libertad. En nuestro análisis se ve que a Felícito le falta el conocimiento acerca del entorno y que carece de cierto conocimiento lingüístico, de modo que no llega a auto-conocerse ni auto-realizarse. Esto se nota también después de las experiencias vinculadas al chantaje y el escándalo en cuanto Felícito reflexiona acerca del futuro: "Ya no estaba él para buscarse otra querida, ni para ir en las noches al bulín a acostarse con las putas. [...]. Cualquiera que fuera el rumbo de su futuro, una cosa era segura: no habría cabida ya en él para el placer ni para el amor. No lo lamentaba, no se desesperaba. La vida era así [...]" (359). Para el transportista no existen ni el azar ni la posibilidad de tomar decisiones propias. Este razonamiento algo patético indica que acepta la vida austera de siempre y se revela así la actitud determinista criticada por Popper (1997, 276): la vida se constituye por causa y efecto, y el individuo solo constituye una pieza mecánica en aquel proceso.

La actitud de Rigoberto es diferente a la de Felícito. El empleado de Ismael escapa los problemas laborales en su tiempo libre escuchando música, leyendo novelas, ensayos y poesía. Así, se entiende que es culto y educado. Su nivel de conocimiento hace que se sienta contento con la vida, pero se queda perplejo en cuanto Fonchito le comenta: "Todos los libros que lees son de escritores europeos [...] Y creo que la mayoría de discos, de dibujos y grabados también” y le pregunta: “¿hay algo que te guste del Perú, papá?” (368). A diferencia de Miguel, Miki y Escobita que traicionan a sus padres, Fonchito usa la ironía contra el suyo cuestionando su afición por la cultura ajena mientras que la propia permanece desapercibida. La ironía que subyace en el cuestionamiento de Fonchito revela que el conocimiento de su padre es delimitado y por tanto resulta ambiguo si llega a auto-realizarse.

En $E H D$, el viaje representa la fase que a los personajes les ofrece conocimiento y, por consiguiente, auto-conocimiento y auto-realización. Sin embargo, a diferencia de los demás que se alegran por el viaje, Felícito parece mostrar escepticismo, bien porque no ve el valor de conocer otras culturas y así conocerse a sí mismo, bien por su actitud determinista, la cual 
Popper (1997, 279 - 82) critica al destacar el azar, los propósitos, los fines y las decisiones por ser fenómenos que no caben en el pensamiento determinista. En estos procesos opera la libertad del individuo, p. ej., la de tomar decisiones propias, siempre en consenso con el entorno, pero sin que nada o nadie le inhiba. A partir de este razonamiento y conforme a Berlín $(1971,146)$ nos permitimos agregar que Armida representa a una persona racional y educada, que tiene la libertad económica y posee la responsabilidad ética. Así ofrece la oportunidad a los demás a obtener conocimiento, auto-realizarse y llegar al consenso frente al entorno. De esta manera se puede decir que vive bajo las condiciones de la libertad positiva.

La conclusión es que en $E H D$ los personajes viven en una democracia, pero bajo una especie de opresión representada por la corrupción y los prejuicios vinculados al machismo. La ironía se configura mediante las reflexiones de los personajes, por las relaciones interpersonales y con el entorno. Por un lado, la ironía sirve para criticar la policía, la prensa y las instancias judiciales de la sociedad democrática por no apoyar a los ciudadanos. Por otro, hace recordar que los ciudadanos en general deban asumir responsabilidad y no aceptar los problemas. A la vez se configura un elogio a los que no dejan someterse, "el héroe discreto" de la sociedad, representado por los protagonistas y la sirvienta Armida. Se deduce que el individuo no solo es una pieza en el proceso de causa y efecto, sino que en la vida operan el azar, nuestros propósitos, elecciones y decisiones. Según este texto de Vargas Llosa, la libertad del individuo es un asunto complejo que no solo depende de la libertad política y económica sino también del auto-conocimiento, la educación y la responsabilidad ética del individuo, calidades que a su vez constituyen la base para auto-realizarse y llegar al consenso.

\section{Bibliografía}

Angvik, Birger. 1987. "Mario Vargas Llosas Theory of the Novel and its Application in Criticism." Ibero-americana Nordic Journal of Latin American Studies Vol XVII: 1 2: $33-26$.

Berlin, Isaiah. 1971. (1969). Four Essays on Liberty. Oxford: Oxford University Press.

Enkvist, Inger. 1987. Las técnicas narrativas de Vargas Llosa. Gotemburgo: Universidad de Gotemburgo.

- 2006. "Siempre fiel a sí mismo: la evolución intelectual de Mario Vargas Llosa." In Antípodas Journal of Hispanic and Galician Studies: 70 años. Estudios críticos sobre Mario Vargas Llosa, vol. I, edited by Boland Osegueda, Roy C. \& Enkvist, Inger, 33 50. Madrid: Editorial Voz.

Estruch, Joan. 2013. “Crítica literaria de la novela 'El héroe discreto' de Mario Vargas Llosa". $\quad E l \quad$ Diario. $\quad$ http://www.eldiario.es/catalunya/diaricultura/heroediscreto_6_178892117.html 10 junio 2017.

Fernández-Lamarque, María. 2016. “'El héroe discreto’ by Mario Vargas Llosa”, Hispania 99, no. 2: $363-364$.

Fromm, Erich. 2016. (1941). El miedo a la libertad. Biblioteca de Psicología, Psiquiatría y Psicoanálisis. 
Goldman March, Francisco. 2015. "Vargas Llosa y su moraleja detectivesca. Crítica literaria de 'El héroe discreto"'. https://www.nytimes.com/2015/03/15/universal/es/vargasllosa-y-su-heroe-discreto.html 5 junio 2017.

Handwerk, Gary J. 1985. Irony and Ethics in Narrative. From Schlegel to Lacan. New Haven: Yale University Press.

Köllmann, Sabine. 2014. A Companion to Mario Vargas Llosa, Woodbridge: Tamesis.

Lafuente, Fernando R. 2013. "'El héroe discreto', de Vargas Llosa: culebrón cervantino." http://www.abc.es/cultura/cultural/20130909/abci-cultural-m104-libros-vargas201309091243.html 27 diciembre 2017.

Marco, Joaquín. 2013. "El héroe discreto. Mario Vargas Llosa." http://www.elcultural.com/revista/letras/El-heroe-discreto/33283 27 diciembre 2017.

Mendoza, M. C. 2014. "El héroe discreto, de Mario Vargas Llosa." https://reginairae.blogspot.se/2014/05/el-heroe-discreto-de-mario-vargas-llosa.html 27 diciembre 2017.

Popper, Karl. 1996. "The Self, Rationality, and Freedom." In Knowledge and the Body-Mind Problem. In Defence of Interaction, edited by M. A. Notturno, 129 - 142. Padstow, Cornwall: T. J. Press.

— 1997. "Indeterminism och mänsklig frihet." In Kunskapsteori, vetenskapsteori, metafysik, samhällsfilosofi, edited by David Miller, 264 - 283. Stockholm: Thales.

Ramírez, Sergio. 2013. "El tercer héroe discreto" El País https://elpais.com/elpais/2013/12/18/opinion/1387391237_564202.html 8 junio 2017.

Tittler, Jonathan. 1984. Narrative Irony in the Contemporary Spanish-American Novel. London: Cornell University Press.

Vargas Llosa, Mario. 2013. El héroe discreto. Madrid: Alfaguara. 